\section{Mikro-Entzündungen fungieren als Trigger Reizdarmsyndrom entschlüsselt?}

\begin{abstract}
> Forscher haben jetzt eine mögliche Erklärung für die Symptome des Reizdarmsyndroms gefunden: Winzige Entzündungen in der Darmschleimhaut aktivieren Mastzellen und enterochromaffine Zellen. Diese produzieren ihrerseits Botenstoffe, die das intestinale Nervensystem sensibilisieren und die Darmschleimhaut zur vermehrten Freisetzung von neu-
\end{abstract}

roaktiven Substanzen (z.B. Serotonin, Histamin und Proteasen) anregen. Die Mediatoren am Ende der Kaskade sowie die Hypersensibilität der Neuronen sind wahrscheinlich für die eigentliche Symptomatik verantwortlich, so die Autoren. Sie belegen ihre These mit In-vitro-Versuchen an mucosalen Zellbiopsien. (cd) Buhner S et al, Gastroenterology 2009, 137:1425

\title{
Bei Blinddarmentzündung nichts überstürzen!
}

\ „Eile mit Weile“ könnte das Motto von Chirurgen in Zukunft bei akuter Appendizitis Erwachsener heißen. Denn eine Analyse von mehr als 30.000

Patientendaten zeigte keine negativen Auswirkungen einer Op. erst nach zwölf Stunden oder noch später nach Klinikauf$10 \int_{2}^{12} 1$ nahme. Zwar erhöhte eine späte Op. die Länge des Ein9 8 765 3 4 griffs und die postoperative Liegezeit geringfügig, jedoch nicht klinisch relevant, wie Experten meinen. So dauerte z.B. die frühe Blinddarmentfernung innerhalb von sechs Stunden ca. 50 Minuten und bei Verzögerung um einen halben Tag und mehr nur fünf Minuten länger. Auch die Morbidität nach Entlassung verschlimmerte sich bei vertagter Behandlung mit 6,1\% versus 5,5\% nur wenig. Grund zum Trödeln liegt bei akuter Appendizitis natürlich trotzdem nicht vor. Im Notfall hängt die Entscheidung über den Op.-Zeitpunkt von der Einschätzung des diensthabenden Arztes ab. Ingraham A et al, Arch Surg 2010, 145:886 Blinddarm-Op. mitten in der Nacht?

Das muss doch nicht sein!

\section{Bringt Knochenschutz Ösophagus in Gefahr?}

> Was ist dran an der Befürchtung, dass die Therapie mit Bisphosphonaten das Risiko für Speiseröhrenkrebs erhöht? Nicht viel, wie irische Forscher jetzt melden. Sie werteten die Daten von über 40.000 Patienten unter BisphosphonatTherapie aus. Das Risiko war nur gering und nicht signifikant erhöht im Vergleich zur Kontrollgruppe. Trotzdem ist Vorsicht geboten: Entwickeln Patienten unter der Therapie Schluckstörungen oder ähnliche Beschwerden, sollten Nutzen und Risiko abgewogen werden. Cardwell CR et al, JAMA 2010, 304:657

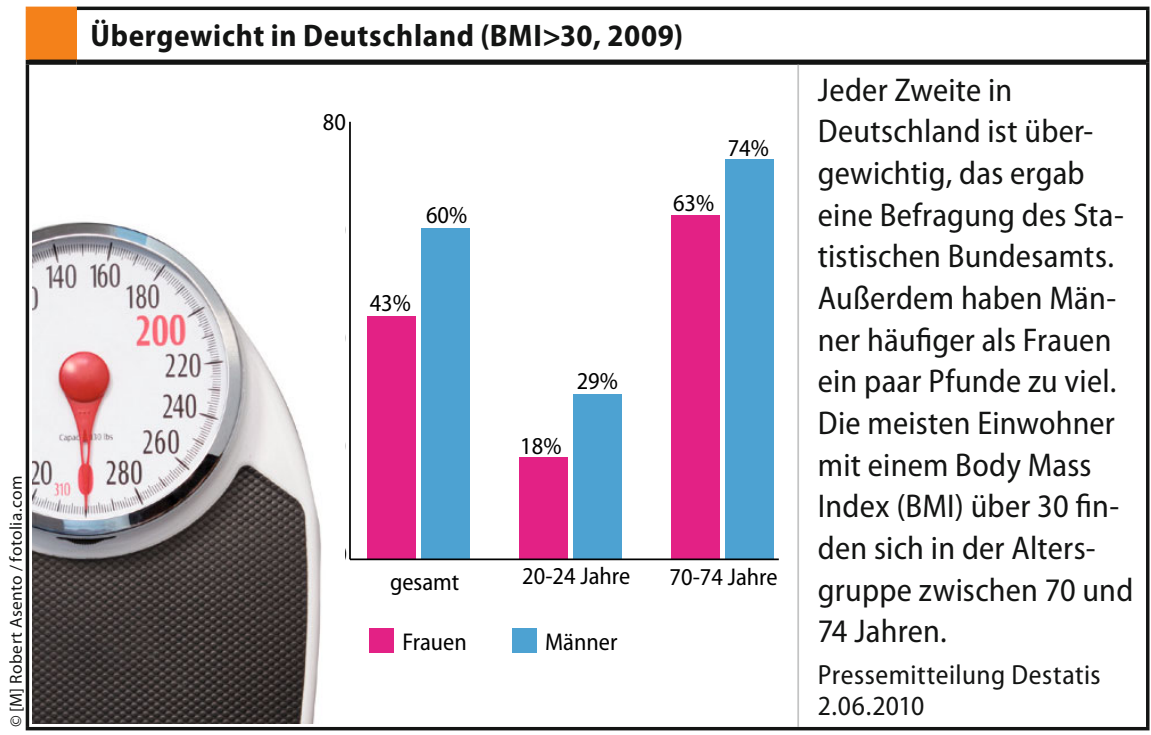

